\title{
Mismanaging Knowledge and Education and their Effects on Employment in Lebanon and the Middle East
}

\author{
Saher H. EL-Annan \\ Arab Open University Beirut, Lebanon \\ sanan@aou.edu.lb
}

\begin{abstract}
Higher education plays an integral role in preparing graduates to enter and adapt, with minimal difficulties, to the work environment. The Lebanese and the wider Middle Eastern industry players' feedback has shed light on the increasing dissatisfaction of the employers with the quality of those who have graduated from local universities. They contend that local graduates are too steeped in theoretical knowledge, and that their technical competencies, as well as their communication and interpersonal skills are found lacking. These graduates need further extensive training before they can be ready to join the work force and adapt to the workplace environment. Hence, and due to the existing deteriorating quality of higher education in the region, there are an increasing number of unemployed graduates. This paper addresses this issue by tackling the challenges that the educational institutions face, in addition to the means that could be adopted to effectively deal with the concerns of the Arab industries.
\end{abstract}

Keywords: Attributes, education, employability skills, learning, and theoretical knowledge

\section{Introduction}

Education is a key and a vital element in the broad development of the nation's youth's capacity to address and solve difficulties. It forms the basis for proactive and positive economic, social, and political changes in the society. It is thus the most important human resource investment that a nation may undertake (Little, 2001). In this age of globalization and modernity, higher education is critical to inducing comprehensive socioeconomic development and corporate rapid change to meet the ever-changing concerns and problems of fresh graduates. The Arab Labor Organization stated that the high unemployment rates among graduates from Arab educational institutions is testament to the widening gulf between university curriculum and the needs and challenges of the business world (Earnest, 2006). Accordingly, a comprehensive and all-inclusive examination of higher education curriculum and policies is necessary to address the challenges posed by the rapid globalization and the needs of the Arab business milieu. Employability skills are the skills needed to gain employment and make positive strides in an enterprise in order to attain individual potentials; consequently, they aid in advancing the enterprise's specific strategic guidelines. Eight employability skills are usually employed. They are communication skills which spur productivity and harmony in relations with clients and preexisting employees; teamwork skills for improved working relations and outcomes; self management skills to add to employees' growth and satisfaction with the job; skills in problem solving and planning; organization skills that spur the generation of constructive results; enterprise and initiative skills are vital in inducing innovations.

It is worth noting that lifelong learning proficiency to acquire the aforementioned new skills coupled with technology skills spurs effective and efficient results and leads to the betterment of the industry's outcomes. (Gonzalez, 2008). These aforesaid skills have several facets that may be adapted in different job roles and disciplines as demanded by the employers, noting that core skills and key competencies, subsets of employability skills, are functional across different fields; for example, workplace relations and social relations. These competencies are multi-functional skills, which are designed to tackle various challenges of daily life. They may be exploited to realize different objectives and address multiple challenges in various settings. Core skills empower graduates to don mental and psychological independence, and enable them to approach daily life actively and reflectively (Gonzalez, 2008). The graduate's attributes are skills, qualities, competencies, and understandings that he/she ought to nurture and develop during university years. Quality 
in education should not be purely theoretical and dependent on mere philosophical viewpoints. It ought to embrace the implemented tools used by corporations. Furthermore, learning occurs in the organization through an organized and unorganized process. Corporate universities are the good examples of an organized learning process established in the organization to expand specific knowledge needed to be competitive at the marketplace (Heyneman, 1997). In the old days, there was a monopoly on knowledge, and universities were the knowledge hubs; whereas, nowadays, learning occurs in a virtual and open access environment, and through networking.

Therefore, it is imperative to merge these three approaches to learning. Hence, corporate, private, and public universities will have to change their business model to encompass virtual learning, open access, and networking environment to survive the market in the Arab region, which will aid in improving the quality of education. Additionally, this combination will encourage intellectual activity and enhance the graduates' curiosity to expand technical capabilities and competence in the sought workplace. The graduates ought to be able to communicate effectively, whether in the realms of effective reading, writing, listening, and speech. University graduates ought to possess a capacity to discover, retrieve and use information in an effective manner. Core skills impart problem-solving skills across different facets and an evident capacity to thrive in group and team settings, generating positive outcomes. Adherence to high ethical and moral standards in their professional and personal life is a key ingredient of employability skills that are demanded from graduates. These attributes are to become inherent in addition to the universities' commitments to social justice, ethical practice, social responsibility, global perspective, appreciation of intellectual and cultural diversity, and capacity to work effectively in multicultural workplaces, and commitment to academic excellence (Kumar, \& Jain, 2010).

\section{Literature Review}

The development of employability skills should be discipline-specific. Experts agree that discipline-embedded approaches are more engaging and end up producing better employability outcomes. This implies that the nurturing, practice, and evaluation of skills and attributes are best attained within the setting of discipline knowledge. As such, the university's faculties are held responsible to develop and appraise the extent to which these skills are being implemented in their respective curriculum, making sure that the said curriculum is flexible and encompasses the expansion of knowledge and practices in the specified field that was brought about because of globalization and innovations and technologies. A big portion of the university students in the MENA region (Middle East and North Africa) study to attain general degrees such as a Bachelor of Arts; such an education, though it paves the way to a plethora of career choices, the broad based nature of these degrees programs makes it virtually impossible to develop discipline oriented approaches to teaching employability skills. The skills taught do not meet specific job roles but a broad base of sense of social responsibility (Bokahos, 2000). Identification of employability skills is a crucial mandate of modern universities, knowing that the attainment of such a goal requires the use of various methods. The techniques used are compatible with the graduates' traits as determined by the level of the college. The employability skills are narrowed down to faculty, school, discipline, and subject level; as for the methods, they encompass discussions with employers, professional entities and students.

It is decidedly desirable to integrate structured methods to map the students' attributes across the different segments of the curriculum for easy access across the entire qualification or program. Such approaches ease the determination of the shortfalls and the configuration of students' traits to discipline-specific content. Many universities in the Middle East and other Arab states have yet to adopt these structured methods and therefore employ sub-optimal techniques of identifying and evaluating employability skills of their students (Ibid). Universities have employed various approaches to develop the graduates' employability skills. To enhance the MENA universities' graduates' employment prospects, appropriate support is to be extended to the academic staff; job skills are to be integrated into the curriculum of the various degrees; and, students, in addition to guidance and counseling, are to be exposed to the work environment via work placements. Furthermore, students are to be encouraged to take active roles in clubs and societies and participate in community ventures. Work Integrated Learning (WIL) ventures in universities are appropriate and effective methods of honing students' job skills. The participation of industry in designing and delivering degree 
programs is a vital factor in uplifting the level of the graduates' employability. Universities became cognizant of the fact that teaching skills is as vital as content tutelage. Hence, staff and lecturers are to now model and develop employability skills via teaching methodologies; such an endeavor requires lecturers to move beyond traditional lecturing and espouse students to a range of approaches when teaching. One thus can surmise that holistic approaches are to be followed in the pursuit of higher learning to develop lifelong learning skills through problems oriented learning, and through promoting values of reflection, articulation, and assessment of learning experiences in the learner. Lecturers are forced to take on various roles, for example, mentor, assessor, coach and facilitator in order to demonstrate core skills to the learners (Earnest, 2006).

Teaching communication skills entails using role playing, working in groups, writing and presenting verbal and written reports. Imparting teamwork skills encompasses the use of learning sets, syndicates, group projects, and communities of practice. Planning and organization skills are taught by data collection and research, planning and organizing functions, developing action plans, time management, and scheduling assignments. Skills of solving problems require the employment of simulations, case studies, designing models, decision making, and using problem solving instruments and methodologies. Enterprise and initiative skills are taught through brainstorming sessions, simulations, change initiatives, and design of innovative solutions and practices. Self-management skills demand the use of work plans, portfolio development and career planning exercises. Learning skills require coaching and mentoring, tools for selfassessment and reflective diaries, and journals. Technology skills are best taught by employing Intran ets and the Internet, industry specific software, equipment and technology to execute tasks and information and communication technology tools (Land, 2001). Universities must develop effective methods of assessing employability skills of their students. Particular skills and their applications as elucidated in the learning objectives of a given course, form strong grounds for such assessment. Supervisors for Workplace Integrated Learning programs are well placed to appraise and provide feedback on a particular student's employability skills. Evaluation reports from these supervisors are then utilized by the university to discern the efficacy and effectiveness of the implemented teaching practices, and the individual performance of the students. MENA universities may employ generic skill testing tools contextualized to the professional discipline; for example, the Employability Skills Profiler and the Graduate Skills Assessment.

These tools permit the students to self evaluate themselves; thus, empowering them to better handles their education and development. Industry players and employers usually have the final say as far as the evaluation of the suitability of the graduates to specific jobs and roles. Assessment in this area may entail the use of different settings and scenarios; for example, group work, how the students carry out presentations, and the student's demeanor during interviews, as well as the student's reactions to different scenarios. These approaches lock out small and medium enterprises that constitute the bulk of employers. The small and medium scale enterprises rely on reports of the graduate's employability skills, for they believe that the quality of teaching constitutes an integral part of the learning experience (World Bank, 2008). Universities in the Middle East ought to integrate graduate attributes and employability skills into their curriculum. Curriculum mapping offers the framework for ascertaining that these attributes are accorded the fitting focus, are discipline oriented and that the content of the course is appropriate. The latter encompasses taught topics, teaching methods, evaluations and examinations, in addition to course objectives, teaching doctrines, and anticipated outcomes. Curriculum mapping evaluates the role of individual courses on the overall objectives of the degree program. This goes beyond examining technical expertise and disciplinary expertise. An entire degree program map identifies gaps and overlaps, and enables the development of broader capacity and attributes. This is difficult to achieve due to the human capital challenges universities in Lebanon and the greater Middle East face as it require additional academic staff to implement. Curriculum mapping enables students to develop an understanding of the expectations of the employers and the relevant skills needed to meet these expectations.

After assessing the student's employability skills, universities need methods to follow when disseminating their reports to the industry; methods that empower students to take charge of their individual employability. Expertise deal with gaps, and pursue relevant techniques of reporting the appropriate segments of this information to potential employers. E-portfolios run by individual students, present universities and the business community with pragmatic ways of enumerating and elucidating their employability skills. There is 
a need to standardize qualifications to meet international standards, for when the student's qualifications are clear, the confusion among industry players is lessened. The universities in MENA may benefit from partnership with professional bodies and industry players if the latter are given a seat on the course advisory committees and the college accreditation of programs committees (Land, 2001). Globalization has led to advances towards liberalization of the higher education in Lebanon and other Middle Eastern Arab states, and the opening up of national labor markets. Higher education is a key segment of the transition to the knowledge economy driven by innovation amongst other factors. This calls for endeavors to integrate industry, science and economy to attain faster economic growth. Competition for qualified labor by industry players requires that universities produce graduates who can compete with graduates from foreign universities and expatriates for existing jobs. The increasingly mobile nature of graduate labor across international borders has compelled the local industry to look for ways to ensure that their products (graduates) can compete in the market (Bruwer, 1998).

Stakeholders in the Arab business world feel that graduates of the education systems in their states within the MENA region appear to be inadequately prepared to handle the challenges of the real business world. The role of higher education in preparing personnel for the job market and fortifying them with apt skills to tackle economic and social challenges cannot be overemphasized. Rapid population growth has resulted in a massive increase in demand for higher education in the past decade in the Arab world. There is great social value attached to university and college education regardless of its utility (El-Berr, \& El-Mikawy, 2004). A great number of universities in the Arab world are isolated from their surroundings, have placed restriction, and constrain interaction regulations on their dealings with the society. The status quo in relations among academic institutions and industry is substantive and fledgling. Interactions among universities and the industrial sector in the Middle East and North Africa is often modest and short term with unrewarding outcomes for both parties. This is a consequence of inertia of the educational systems in the MENA region. There is an urgent need to foster and nurture mutually symbiotic relations among the educational elites (students, faculty staff, researchers and graduates) and the industry players (mangers and staff) to realize transformation; such an enhanced relation would surely lead to the reform of the curriculum, and consequently would mirror realities on the ground and make education more relevant and in tune with the needs of the industry. The industry is hesitant to establish working relations with academic institutions.

It is seemingly led by the erroneous assumption that universities are there to teach the basics and not practical applications. Faculty and students' involvement in analyzing, understanding and seeking solutions for real problems will go a long way in bettering and implementing learnt theories. Institutions of higher learning in MENA region must seek ways to induce industry to participate in molding academic curriculum, for such an endeavor would act as a means to check the taught skills and give training that is more relevant on attachment to students and fresh graduates (Stromquist, 2002). Governments have been pursuing policies tailored to realize universal access to basic education for all their citizens. The UN Convention on the Rights of the Child advocated the assessment of education in terms of impacts on behavior and health, productivity and access to employment. Secondary and tertiary education is critical in nurturing capacity and skills needed in knowledge based economies. This is followed by the improvement in quality of this education to ensure that the graduates are imbued with a solid grounding in humanities and sciences, logical thinking skills, and passion for learning which forms the core of human development envisioned in Islam (Zajda, 2005). Higher education in MENA plays a crucial role in creating the building blocks for the modern state and readying a competent workforce to join various economic fields. It does this in the face of various challenges, which constrain its ability to meet modernity's needs and surmount challenges (Melonio, \& Mezouaghi, 2001). Rapid population growth has fueled an increase in enrolment of students in MENA universities.

Universities have imposed strict admission guidelines and requirements in an attempt to stem the numbers of students attempting to join their institutions. Universities in MENA are situated in central regions of their respective states, e.g. Lebanese universities are mostly in Beirut, restricting access to populations in peripheral areas (Angel-Urdinola, \& Semnali, 2010). Universities in the Middle East and North Africa are primarily funded by their respective governments. These governments allocate inadequate resources to fund the activities of these universities. Some governments have even decreased funding for higher education institutions. Exportation of Arab wealth to universities in foreign countries of Europe and North America has 
further aggravated this problem of funding. Wealthy citizens are spending huge amounts for educating their offspring in the western universities, while local universities remain under-funded and cash strapped. Reduced government spending on higher education lowers the living standards of university's staff and minimizes their drive to come up with advance innovative methodologies (Sayed, 2006). Most Lebanese and MENA universities remain secluded from their environment and have limited contact with their surrounding societies. This constricts their ability to research and address challenges facing individuals and businesses in a said society. This separation has led to academia being out of touch with reality, and has created a discrepancy between the interests of the universities and that of the societal concerns. The curricula in these universities are majorly philosophical and theoretical, and tend to have disharmony between their goals and content. These universities must make consistent and sustained efforts towards marrying the skills the students learn and the needs and difficulties facing local businesses (Herrera, \& Torres, 2006).

Scholars, university lecturers and students in most states of the Middle East and North Africa have restricted academic freedoms of thought, expression and opinion. Many of the Arab societies are generally closed with governments being highly sensitive to criticism of any form from any quarter. Governments thus usually clamp down on perceived dissidents in universities; thus, curtailing the freedom of thought. Higher education institutions have been acknowledged worldwide to be altars of free expression of thoughts and ideas. Students and staff must be permitted to exercise their minds and mull over societal challenges and be able to meaningfully support their opinions. Most universities in MENA are state owned. They rely on the government for administrative and financial backing. The governments in turn impose inflexible regimes that result in unsound practices that usually lower the status of these institutions. State influence constrains academic freedoms, broad participation in decision making, free publishing and freedom of expression of opinions; subsequently, scholarly invention and innovation. Tension-packed working environments and unstable states of individual security stifle creativity and encourage aloofness of institutions to prevailing concerns of the society. The state's control of the education purse is one of the principal grounds for the declining standards of university education in MENA (Shaw, 1997).

\section{Methodology and Results}

Scholarly research conducted by university students and faculty highlights issues and derives hypotheses and deductions. This research frequently provides a means via which social, economic, and cultural treasures may be discovered and effectively and productively exploited. Research undertaken by institutions of higher learning often makes valuable contributions towards the development of a problem solving mentality, encouraging ventures previously not considered. Research is thus not restricted to theoretical projects; it can and should seek practical application. Research infrastructure in Arab universities is in a sorry state. Lecturers and other think tanks have little motivation to undertake research on critical issues related to business. Dedication to scholarly research in these institutions invites derision and contempt from colleagues. Ubiquitous threats of censorship and limited interest conspire to stifle research activities in many MENA universities (Axelrod, 2002). Higher education colleges have made inadequate efforts to create institutional frameworks that may permit, encourage and hasten coordination, commutation and sharing of ideas among various fields. This situation is further exacerbated by inadequate funds availed to support research activities. Arab states in MENA spend about half a percentage of the gross domestic product on research. This is significantly less than the internationally recommended minimum of two percent. Many Arab universities have ambiguous research policies. Research conducted in these institutions has no apparent goal of addressing or attending to the needs of the institution or society. Consolidation of research policy will avail objective supervision to guide concerted and coordinated research efforts (Gonzalez, 2008).

Education is a fundamental drive for uplifting individuals culturally, intellectually and economically. Higher education is integral to socioeconomic development. This demands that the quality of education goes beyond the conventional levels (at least in MENA) of attaining knowledge to teaching the pertinent competencies and skills. In the MENA region, it appears that the higher the level of academic qualification, the higher is the rate of unemployment. The public sector in western Asia, especially the gulf, has been directly absorbing graduates from local universities. However, increased enrolment has saturated this system of employment. In some gulf states, more than two thirds of the workforce employed by the private sector is of foreign origin in 
spite of the presence of local graduates. This is indicative of the inadequacy of relevant skills of the graduates of the local institutions of higher learning. The Youth Employment Summit for Western Asia 2002 observed that education and skills taught in Gulf universities had limited significance to the needs and requirements of the labor market (Roberts, Gentry, \& Townsend, 2006). The fraction of Egyptians with university education has significantly increased in the past decade. The country, previously, had a policy to absorb university graduates into the public sector, which has since been suspended. This has decelerated the pace of growth of the public sector and severely and negatively affected the employment prospects of fresh women graduates, though many Arab women graduates usually aspire to join the public service. This is true as well for other countries in the region (Little, 2001).

Employers in the MENA region have high concerns as to the high instances of mismatch of skills to be a serious constraint to seamless economic activity. This is prevalent in the Arabian Gulf, North Africa and Lebanon. Mismatch between skills possessed by university graduates and skills needed by employers in the real world are symptomatic of the malaise of low quality standards afflicting these institutions. Employers in the manufacturing industry lament that graduates from local institutions of higher learning are underqualified and do not have the appropriate practical experience. Higher education in MENA is geared towards the acquisition of academic certificates with relevant programs for imparting job skills playing only a marginal role. More than two thirds of university graduates specialize in social sciences and humanities. The social scientists and humanities experts churned by universities are suited for government jobs and ill suited for the private manufacturing and service sectors (Cleary, Flynn, Thomasson, Alexander, McDonald, 2007). A major cause of disaffection and dissatisfaction by employers of their fresh graduate employees appears to be the employees' perceived lack or inadequate soft skills. These soft skills include social graces, communication skills, personality traits and individual habits, interpersonal skills, and language habits. Employers require people with not only basic knowhow but also skills. They require their employees to have substantive cognitive skills that enable them to be able to keep adding to their knowledge, and to think constructively. Potential employees must be willing to get their hands dirty and be meticulously attentive to detail. The existing situation only promotes a cursory passing examination (Cleary, Flynn, Thomasson, Alexander, McDonald, 2007).

The world is changing at an extremely fast pace. Relevant knowledge is surpassing physical capital as a source of better living standards for local populations. Technology in the form of information technology, internet, and innovations comprises the principal drivers of development. Companies are increasingly doing most of their businesses online and through other information and communication technology infrastructure. Arab universities must therefore be prepared to teach their students practical information and communication technology applications that are relevant to their chosen disciplines (Daun, 2002). Partnerships between universities and the private sector are vital to improve the quality of training provided by the Arab universities. Engagement with industry and cultural institutions and Islamic scholars enables students to better their employability skills. Professional bodies for professions such as engineers, architects, nurses and accountants become the custodians of the curriculum. For example, a university offering accounting degrees may liaise with local accounting professional bodies to ensure that graduates procure a number of exemptions when pursuing professional certified public accountant examinations. Career departments are to be established in the universities and be equipped with professional staff who could give career guidance to students. Universities and the private sector decipher employment trends and their impacts on employability (Barro, \& Jong-Wha, 2000).

Employers expect graduates to possess an assortment of skills that will facilitate the latter's smooth entry into the workplace. A skill is an ability gained from training. Training can be gleaned from training manuals, books and other texts or it may be gained through practice. Many global corporations and businesses demand that graduates be equipped with a range of skills useful to their career of choice. Employers bemoan the fact that they presently have to conduct two-year in-house training for fresh graduates in order to uplift the latter interpersonal skills. Some business organizations have undertaken cost cutting measures and down sized their work force, so, their training and support facilities are therefore minimal and can only be outsourced; a fact that leads to the elimination of crucial mentoring for new employees. Employees who had received inadequate training in interpersonal skills while at college experience difficulty in adjusting to the new 
regime (Zajda, 2005). Universities in the Arab Middle East have courses in their curriculum that touch on people's skills. However, the period they allot for teaching these courses is insufficient to enable graduates to frictionless adapt to the work environment. This demands that graduates should have undertaken intensive industrial attachments to better their interpersonal skills. Many fresh graduates exhibit dissatisfactory levels of interpersonal skills in applications of the work environment such as team or group assignments. The interpersonal skills of local university graduates are still immature, unlike the level that is exhibited by graduates of western European and American universities. Holders of Master of Business Administration degrees from local entities are normally placed in administrative positions that demand the utilization of analytical skills, and not in managerial positions, which entail the application of interpersonal skills.

This fact confirms that Arab employers perceive local graduates to have inadequate interpersonal skills. Course providers must strive to find effective techniques of imparting interpersonal skills grounded on emotional intelligence pedagogy (Kumar, \& Jain, 2010). Graduates and employers often have differing attitudes towards each other's work environment. Attitude refers to the frame of mind, approach, point of view, perception, and outlook. Employers typically believe that the work of graduates has insufficient complexity. Graduates often find it belittling to have to do mundane tasks at the office; yet, these tasks are critical to their developing pragmatic interpersonal skills. Some employers feel that degree programs in local universities do no push students hard enough. The hours that the students put into their studies is insignificant compared to the demands of the workplace. Fresh graduates are frequently taken aback by the hours that work demands that they put in. In addition, the internships programs and field tours organized by their business schools are inadequate in acquainting students with the rigors of the work environment that they would later confront. Many business organizations do not allow university students to undertake internship opportunities as they do not acknowledge its importance. Accordingly, effective partnership between employers and business organizations is vital throughout the internship process to improve the quality of such a partnership and its value to the different parties (Teichler, 2001).

\section{Conclusion}

University education in the Middle East and North Africa must be made to be more responsive to the demands of the local and global economy. Globalization has opened up this market to labor from foreign countries. Employment saturation and the global economic crisis have conspired to ensure the suspension of direct absorption of graduates into state employment directly from universities. Private sector employers are in need of new employees who have not only the technical knowhow, but also employability skills and excellent interpersonal relations. This calls for the adoption of strategies to increase investment in academic staffing; and, to adopt a new range of teaching approaches, techniques of identifying, developing, in order to better asses the graduate's attributes and employability skills.

Recommendations: Higher Ministries of Education must re-examine universities' curricula, and restate new policies to be implemented in certain courses to meet the challenges posed by the workplace environment. Universities ought to establish a department that deals with the needs of core skills required to empower graduates to adapt to the challenges of business's daily activities. MENA universities are to adopt realistic case studies where problem solving involves a team of candidates rather than individuals; such studies encourage the students to be effective team players, and would increase the channels of communications amongst them. Universities should constantly assess its methods of implementing employability skills in their students. Corporate, private, and public universities will have to change their business model to encompass virtual learning, open access, and networking environment; hence, enabling their graduates, as well as themselves as institutes, to survive in the business market.

\section{References}

Angel-Urdinola, D. \& Semnali, A. (2010). Labor Markets and School-to-Work Transition in Egypt: Diagnostics, Constraints, and Policy Framework. World Bank. MPRA Paper, 27674.

Axelrod, P. (2002). Values in Conflict: The University, the Marketplace and the trials of Liberal Education. McGill- Queen's Press. 
Barro, R. J. \& Jong-Wha, L. (2000). International Data on Educational Attainment: Updates and Implications. NBER Working Papers Series 7977. National Bureau of Economic Research. Cambridge, MA.

Bokahos, K. A. (2000). Trends to Develop the Higher Education under the Shadow of Globalization. AlTa'awan (Journal of Collaboration), 51, 51-88.

Bruwer, J. (1998). First Destination Graduate Employment as Key Performance Indicator: Outcomes Assessment Perspectives. Institutional Planning and Research. Cape Town, RSA.

Cleary, M., Flynn, R., Thomasson, S., Alexander, R. \& McDonald, B. (2007). Graduate Employability Skills. Business, Industry and Higher Education Collaboration Council. Melbourne. Commonwealth of Australia.

Daun, H. (2002). Educational Restructuring in the Context of Globalization and National Policy. New York. Routledge.

Earnest, J. (2006). Education Reform in Societies in Transition: International Perspectives. Sense Publishers.

El-Berr, S. \& El-Mikawy, N. (2004). Regional Perspectives on Education Reform in the Arab Countries.

Gonzalez, G. (2008). Facing Human Capital Challenges of the 21st century: Education and Labor Market Initiatives in Lebanon, Oman, Qatar, and the United Arab Emirates. Rand Corporation.

Herrera, L. \& Torres, C. A. (2006). Cultures of Arab Schooling: Critical Ethnographies from Egypt. SUNY Press.

Heyneman, S. (1997). The Quality of Education in the Middle East and North Africa.

Kumar, D. \& Jain, V. (2010). Survival Skills of Business Management Graduates: A Study with Reference to Retail and Banking. Far East Journal of Psychology and Business, 1(1).

Land, R. (2001). Agency, Context and Change in Academic Development. International Journal for Academic Development, 6(1).

Little, B. (2001). Reading Between the Lines of Graduate Employment. Quality in Higher Education, 7(2).

Melonio, T. \& Mezouaghi, M. (2001). Financing Higher Education in the Mediterranean Region: The Case of Egypt, Lebanon and Tunisia. Agency Francaise de Development.

Roberts, J., Gentry, D. \& Townsend, A. (2006). Student Perspectives: Evaluation a Higher Education Administration Program. Journal of Case Studies in Education, 1-20.

Sayed, F. H. (2006). Transforming Education in Egypt: Western Influence and Domestic Policy Reform. Cairo. American University in Cairo Press.

Shaw, K. E. (1997). Higher Education in the Gulf: Problems and Prospects. Exeter. University of Exeter.

Stromquist, N. P. (2002). Education in a Globalized World: The Connectivity of Economic Power, Technology, and Knowledge. Rowman \& Littlefield.

Teichler, U. (2000). New Perspectives of the Relationship between Higher Education and Employment. Tertiary Education and Management. 6(2), 79-92.

World Bank. (2008). The Road Not Travelled, Education Reform in the Middle East and North Africa, World Bank, Washington DC.

Zajda, J. I. (2005). International Handbook on Globalization, Education and Policy Research: Global Pedagogies and Policies. Sydney. Springer. 